\title{
Ellipsometry-Based Biosensor for Label-Free Detection of Biomolecular Interactions in Microarray Format
}

\author{
Yung-Shin Sun ${ }^{*}, 1,2$ and Xiangdong Zhu² \\ ${ }^{1}$ Department of Physics, Fu-Jen Catholic University, New Taipei City 24205, Taiwan \\ ${ }^{2}$ Department of Physics, University of California at Davis, Davis, CA 95616, USA
}

(Received June 10, 2013; accepted August 22, 2013)

Key words: biosensor, high throughput, label-free detection, microarray, biomolecular interaction, oblique-incidence reflectivity difference

Microarrays of biological molecules are useful tools for discovery and functionality characterization in fundamental and applied research of genomics, proteomics, glycomics, and cytomics. They provide a high-throughput platform that enables parallel studies of hundreds to tens of thousands of distinct biomolecular reactions. Usually, the characterization of binding reactions between surface-immobilized targets and solutionphase analytes involves fluorescence-based detection methods. However, labeling analytes inevitably changes innate properties of the molecules and, in turn, modifies analyte-target interactions often in an uncharacterized manner. As a result, label-free microarray detection is desirable. In this study, optical microscopes based on the obliqueincidence reflectivity difference (OI-RD) technique are developed and used to detect biomolecular interactions in microarray format. OI-RD, a most sensitive form of optical elliposometry, measures the difference in reflectivity change (both magnitude and phase) between two polarized components of an optical beam. Such a difference is related to the thickness and dielectric constant of surface-immobilized biomolecules. Here, we report the use of such microscopes to study novel protein-protein, oligosaccharide-protein, and small molecule-protein interactions. These experimental results demonstrate that the OI$\mathrm{RD}$ microscopes can serve as powerful tools in biosensing, high-throughput screening, and other applications in biophysics, biochemistry, and biomedical engineering.

\section{Introduction}

Many complex and diverse interactions among molecules drive our daily metabolism and vital activities. There are hundreds of thousands of different proteins in each of our cells. These proteins function properly by interacting with other biomolecules. Cell

*Corresponding author: e-mail: 089957@mail.fju.edu.tw 
duplication and growth, tissue generation and development, and even defense against and recovery from all kinds of diseases are triggered and carried out through sequential, stepby-step biomolecular interactions. Hence, in modern cell biology and molecular biology, one of the major challenges is to experimentally determine biomolecular interactions and how they are altered by molecular stimuli and other intra- and intercellular processes. These interactions in living cells are much more complex as many of them occur concurrently in dynamic equilibrium. Changes in concentrations (e.g., expression level) and/or reaction rate constants (due to chemical or structural changes induced by internal or external stimuli) of a small set of biomolecular constituents can profoundly alter the equilibrium and, in turn, the state of a living cell. Since the number of concurrent and sequential biomolecular reactions is very large, experimental techniques that enable highthroughput detection of these reaction rate constants are highly desirable. In this paper, we report the use of a combination of the microarray platform and oblique-incidence reflectivity difference (OI-RD) microscopes for high-throughput and label-free detection of biomolecular interactions.

A microarray is composed of sub-millimeter-sized spots of biomolecules arranged in a regular pattern on a solid substrate. These biomolecules can be DNAs, RNAs, proteins, peptides, small molecules, carbohydrates, and even cells or tissues. There are many advantages to using such a microarray format for characterizing the interaction of a large number of biomolecular targets with a single molecular or viral or even cellular probe. First, the consumption of targets is very small. Second, in a microarray format, hundreds to tens of thousands of biomolecular reactions can be investigated simultaneously. Thirdly, the interaction of a solution-phase probe with "immobilized" targets mimics many (if not most) biomolecular reactions that occur in vivo when one of the participating reactants is usually attached to an "immobile" substrate or scaffold. These include syntheses of proteins on ribosomes attached to the endoplasmic reticulum, protein reactions with carbohydrates on liposome or lipids on cell membranes, DNA replication, and DNA repair processes.

Fluorescence-based techniques have been widely used in microarray readouts for their superior sensitivity, low background, and large selection of fluorescent tags. However, labeling probes inevitably change the intrinsic characteristics of probe-target interactions and subsequent biological processes that involve either the target or the probe or both. To do away with fluorescence-based detection, we have developed OI$\mathrm{RD}$ microscopes based on polarization-modulated nulling ellipsometry for label-free detection of biomolecular microarrays. These microscopes work with large microarrays on regular microscope glass slides without requiring any special metallic, semiconductor, or oxide coating.

Previously, OI-RD microscopes have been applied to study various protein-protein, ${ }^{(1,2)}$ sugar-protein, ${ }^{(3)}$ and small molecule-protein interactions ${ }^{(4-7)}$ in the microarray format. To further demonstrate the feasibility and applicability of these microscopes, here, we report their use in studying (1) the interactions between vascular endothelial growth factor (VEGF)/kinase insert domain-containing receptor (KDR) and their antibodies, (2) the interactions between oligosaccharides and lectins, and (3) the interactions between small molecules and cell lysate/cDNA phage. 
Studying the interactions between VEGF/KDR and their antibodies: VEGF is a protein that plays an important role in angiogenesis, the formation of new blood vessels from the endothelium of a preexisting vasculature. As its name indicates, VEGF stimulates the growth, survival, and proliferation of vascular endothelial cells. VEGF has been shown to facilitate the survival of existing vessels, contribute to vascular abnormalities, and stimulate new vessel growth. ${ }^{\left({ }^{-12}\right)}$ The endothelial activities of VEGF are mediated by the activation of 2 receptor tyrosine kinases: fms-like tyrosine kinase (Flt-1 or VEGFR-1) and kinase-insert-domain-containing receptor (KDR or VEGFR-2). The equilibrium dissociation constant $\left(K_{D}\right)$ for KDR binding to VEGF has been reported to be $75-770 \mathrm{pM},^{(13-16)}$ which is $10-100$ times larger than that for Flt-1 binding to VEGF (about $10 \mathrm{pM}^{(13,17)}$ ). Although it has a higher affinity compared with KDR, Flt-1 has a much lower kinase activity to VEGF. This suggests that the angiogenic effects of the VEGF family are exerted mainly through the interaction of VEGF with the receptor KDR. ${ }^{(18,19)}$ However, overexpression of VEGF can lead to diseases such as cancer, psoriasis, arthritis, endometriosis, and diabetic retinopathy. By increasing the expression of VEGF, solid tumors can develop to a size of 2-3 mm in diameter (which exceeds the limit of size without an adequate blood supply) for the purposes of growth and metastasis. To decrease the expression of VEGF and thus reduce the activity of tumors, it is crucial to find ways to inhibit the VEGF/receptor pathway. Basically, there are two main strategies: inhibiting either the VEGF itself or the VEGF receptor. AntiVEGF strategies that specifically target the VEGF with anti-VEGF antibodies inhibit only the VEGF pathway without disturbing other "off-target” pathways. ${ }^{(20,21)}$ Anti-VEGF strategies that target the receptor, such as KDR, with its antibodies or inhibitors may accidentally affect other secondary pathways mediated via the same receptor. ${ }^{(20-22)}$ In this study, we report a microarray-based, real-time detection of VEGF and KDR reactions with their corresponding antibodies. The affinity constants of these antibodies to VEGF and KDR are determined. The results could be used to determine the efficiency, stability and durability of these antibody-based drug candidates as anti-VEGF therapies.

Studying the interactions between oligosaccharides and lectins: Human milk, a complex biofluid containing mainly sugars, proteins, and lipids, is abundant in free oligosaccharides at concentrations of $5-10 \mathrm{~g} / \mathrm{L} .{ }^{(23)}$ The building blocks of human milk oligosaccharides (HMOs) include D-glucose (Glu), D-galactose (Gal), $N$-acetylglucosamine (GlcNAc), L-Fucose (Fuc), and sialic acid ( $N$-acetyl neuraminic acid (Neu5Ac) in humans, and both Neu5Ac and $N$-glycoyl neuraminic acid (Neu5Gc) in other species). ${ }^{(24)}$ HMOs are nondigestible saccharides that have been shown to protect infants against infection and also support the development of their immune systems. ${ }^{(25-27)}$ Recently, HMOs have been demonstrated in vitro to reduce the transfer of the human immunodeficiency virus (HIV-1) from mothers to children.( ${ }^{28,29)}$ It is important to fully analyze all HMOs and characterize their corresponding structures and functions. However, this remains a major challenge simply because of the large number of oligosaccharides and the complexity of their structures. To date, more than 200 HMOs have been identified, including some with molecular weights up to $6,000 \mathrm{Da}{ }^{(30,31)}$ Currently, high-performance liquid chromatography (HPLC), high-pH anion-exchange chromatography (HPAEC), and mass-spectrometry (MS) are the most widely used 
instruments for characterizing the structures of oligosaccharides in human milk.(32-35) In the present study, $12 \mathrm{HMOs}$ with different mass-to-charge $(\mathrm{m} / \mathrm{z})$ ratios were profiled and separated using the HPLC-Chip/MS technology described in the literature. ${ }^{(36,37)}$ These 12 HMOs, together with 4 control oligosaccharides, were aminated for immobilization on epoxy-coated glass slides as a carbohydrate microarray. This microarray was further reacted with 3 lectins for determining the binding affinities of specific lectinoligosaccharide interactions.

Studying the interactions between small molecules and cell lysate/cDNA phage: Cell lysate, a fluid containing the breaking down of cells, is applied in Western and Southern blotting to analyze the compositions of proteins, lipids, and nucleic acids. Screening small molecular microarrays (SMMs) against cell lysates provides direct ways to detect and characterize the interactions between small molecules and specific proteins such as proteases. ${ }^{(38)}$ In this study, 83 biotinylated small molecules were immobilized on streptavidin-coated glass slides as SMMs for screening against Jurkat cell lysates. These small molecules were identified as strong ligand candidates to intracellular proteins of Jurkat cells. ${ }^{(39)}$ In addition, complementary DNA (cDNA) phages used to display and select the present small molecules were reacted with the SMM. The screening results indicate that all 83 small molecules bind specifically to cell lysates and cDNA phages with different uptakes and affinities.

\section{Materials and Methods}

\section{$2.1 V E G F / K D R$ experiment}

Protein targets and probes: VEGF ( $\mathrm{F}_{\mathrm{c}}$-conjugated), KDR ( $\mathrm{F}_{\mathrm{c}}$-conjugated), antibody against VEGF (anti-VEGF v-6-2), and antibody against KDR (anti-KDR v1) were obtained from Epitomics (Burlingame, CA). All reagents were dissolved and diluted in 1× PBS as protein targets and/or probes.

Preparation of target microarrays: Microarrays were fabricated on epoxy-coated glass slides (CEL Associates, Pearland, TX) with an OmniGrid 100 contact-printing arrayer (Digilab, Holliston, MA, USA). The microarray was composed of VEGF at a printing concentration of $0.6 \mathrm{mg} / \mathrm{ml}, \mathrm{KDR}$ at a printing concentration of $3.4 \mathrm{mg} / \mathrm{ml}$, antiVEGF v-6-2 at a printing concentration of $2.5 \mathrm{mg} / \mathrm{ml}$, and anti-KDR v2 at a printing concentration of $2.73 \mathrm{mg} / \mathrm{ml}$. All microarray-bearing slides were stored as printed in slide boxes for at least $24 \mathrm{~h}$ before further processing.

\subsection{Oligosaccharide-lectin experiment}

Aminated oligosaccharides: $12 \mathrm{HMOs}$ with different $\mathrm{m} / \mathrm{z}$ were analyzed and separated as described in the literature. ${ }^{(36,37)} 3$ known oligosaccharides, NNN, Hex, and Hept, were purchased from Sigma-Aldrich (St. Louis, MO). All oligosaccharides were aminated and dissolved in $1 \times$ PBS as targets for microarray printing. The mass (aminated and neutral $\mathrm{m} / \mathrm{z}$ ratios) and composition (numbers of hexose, HexNAc, and fucose groups) of these aminated oligosaccharides were analyzed by mass spectrometry and the results are listed in Table 1.

Preparation of target microarrays: 16 aminated oligosaccharides listed in Table 1 were dissolved in $1 \times$ PBS to $100 \mu \mathrm{M}$ for microarray printing. Using an OmniGrid 
Table 1

Mass and composition of aminated human milk oligosaccharides.

\begin{tabular}{|c|c|c|c|c|c|c|c|}
\hline $\begin{array}{l}\text { Sample } \\
\text { name }\end{array}$ & Aminated $\mathrm{m} / \mathrm{z}$ & Neutral $m / z$ & $\begin{array}{c}\text { Number of } \\
\text { hexose }\end{array}$ & $\begin{array}{c}\text { Number of } \\
\text { HexNAc }\end{array}$ & $\begin{array}{l}\text { Number of } \\
\text { fucose }\end{array}$ & $\begin{array}{c}\text { Number of } \\
\text { NeuAc }\end{array}$ & Source \\
\hline 1 & 774.3203 & 707.2484 & 3 & 1 & & & HMO \\
\hline 2 & 920.3782 & 853.3063 & 3 & 1 & 1 & & HMO \\
\hline 3 & 1139.4525 & 1072.3806 & 4 & 2 & & & $\mathrm{HMO}$ \\
\hline 4 & 1285.5104 & 1218.4385 & 4 & 2 & 1 & & $\mathrm{HMO}$ \\
\hline 5 & 1431.5683 & 1364.4964 & 4 & 2 & 2 & & $\mathrm{HMO}$ \\
\hline 6 & 1577.6262 & 1510.5543 & 4 & 2 & 3 & & $\mathrm{HMO}$ \\
\hline 7 & 1650.6426 & 1583.5707 & 5 & 3 & 1 & & HMO \\
\hline 8 & 1796.7005 & 1729.6286 & 5 & 3 & 2 & & $\mathrm{HMO}$ \\
\hline 9 & 1942.7584 & 1875.6865 & 5 & 3 & 3 & & $\mathrm{HMO}$ \\
\hline 10 & 2161.8327 & 2094.7608 & 6 & 4 & 2 & & $\mathrm{HMO}$ \\
\hline 11 & 2307.8906 & 2240.8187 & 6 & 4 & 3 & & $\mathrm{HMO}$ \\
\hline $12(\mathrm{NNN})$ & 694.3206 & 627.2487 & & 3 & & & Sigma \\
\hline 13 & 700.2836 & 633.2116 & 2 & & & 1 & Dextrin \\
\hline 14 (Hex) & 1057.3994 & 990.3275 & 6 & & & & Sigma \\
\hline 15 (Hерt) & 1219.4522 & 1152.3803 & 7 & & & & Sigma \\
\hline 16 (Mix) & $774-2307$ & $707-2240$ & & & & & $\mathrm{HMO}$ \\
\hline
\end{tabular}

100 contact-printing arrayer, 2 replicates of each of the 16 aminated oligosaccharides were printed on epoxy-coated glass slides. By contact printing 10 times at each target location, a sufficient volume of the target solution was deposited over an area of $100 \mu \mathrm{m}$ in diameter.

Protein probes: All lectins were received as gifts. ConA (Canavalia A, from Canavalia ensiformis) binds to hexose-containing oligosaccharides such as those with glucose (Glu) and/or mannose (Man). ${ }^{(40)}$ WGA (whole germ agglutinin, from Triticum aestivum) interacts with HexNAc-containing oligosaccharides such as those with $\mathrm{N}$-acetylglucosamine (GlcNAc). ${ }^{(40)}$ LTA (lotus lectin, from Lotus tetragonolobus) binds to fucose-containing oligosaccharides. ${ }^{(41)}$ As protein probes, ConA and TLA were dissolved in Tris buffer ( $\mathrm{pH}$ 7.3, $0.05 \mathrm{M}$ Tris, $0.15 \mathrm{M} \mathrm{NaCl}, 0.1 \mathrm{mM} \mathrm{CaCl}_{2}, 0.01 \mathrm{mM}$ $\mathrm{MnCl}_{2}$ ), and WGA was dissolved in $1 \times$ PBS buffer.

\subsection{Small molecular microarray experiment}

Small molecule targets, cell lysate and cDNA phage probes: Using the onebead one-compound (OBOC)-based phage display assay, ${ }^{(42-46)} 83$ small molecules were identified as candidate ligands to intracellular proteins of Jurkat cells. Each of these small molecules was further conjugated to a biotin molecule via a flexible linker and dissolved in dimethyl sulfoxide (DMSO) for immobilization on streptavidincoated surfaces. Highly spun cell lysates (mixed with deoxyribonuclease (DNase) and ribonuclease (RNase)) and purified cDNA phages were received as a gift.

Preparation of target microarrays: Using an OmniGrid 100 contact-printing arrayer, 83 biotinylated small molecules were printed into 2 batches of microarrays (42 
in the first batch and 41 in the second batch) on streptavidin-functionalized glass slides (ArrayIt, Sunnyvale, CA). The printing concentration for all small molecules is 0.25 $\mathrm{mM}$. The microarray-bearing slides were stored as printed in slide boxes for at least $24 \mathrm{~h}$ before further processing.

\subsection{OI-RD scanning microscope for label-free microarray detection}

The detailed working principle of the OI-RD scanning microscope used in the present work was described in earlier publications. ${ }^{(2,7)}$ It directly measures the differential changes between the $p$-polarized component and the s-polarized component of the reflected light (see the middle top of Fig. 1). Such a difference is proportional to the surface mass density change brought about by the captured probe molecules. The OI-RD image of a microarray was acquired by moving the sample stage two-dimensionally with a linear step size of $20 \mu \mathrm{m}$ in both directions (see the left of Fig. 1). To acquire real-time binding curves, we measured the OI-RD signals from one pixel of a printed spot (target pixel) and one pixel of the unprinted region adjacent to the target (reference pixel) and took the difference as one time point of the binding curve (see the right of Fig. 1). This procedure reduced the contribution of the drift in the optical system to the binding curve measurement. This was repeated at a time interval shorter than the characteristic time of the reaction.

\subsection{Experimental setups and procedures}

The microarray-bearing glass slide was assembled in a fluidic chamber $(30 \mu \mathrm{L}$ in active volume) and washed with $1 \times$ PBS. Afterward, we replaced the $1 \times$ PBS buffer in the chamber with a solution of probe in buffer at a flow rate of $30 \mathrm{~mL} \mathrm{~min}^{-1}$ for a few seconds and then reduced the flow rate to $0.01 \mathrm{~mL} \mathrm{~min}^{-1}$ for a period of time (association phase). Subsequently, we replaced the reagent solution with buffer only at a flow rate

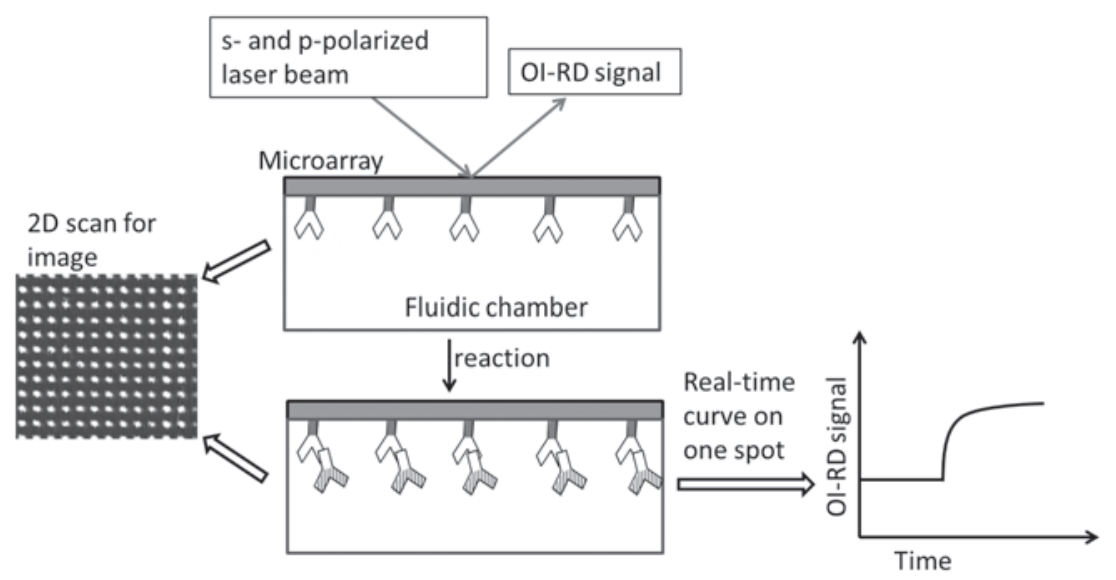

Fig. 1. Middle: The OI-RD signal is the difference between the reflectivities of the $s$ - and p-polarized components of the laser beam. Left: An OI-RD image of a microarray is acquired via 2D scan. Right: Real-time binding curve of a selected microarray spot. 
of $30 \mathrm{~mL} \mathrm{~min}^{-1}$ for a few seconds and then reduced the flow rate to $0.01 \mathrm{~mL} \mathrm{~min}^{-1}$ to observe the dissociations of the captured probe (dissociation phase). Rate constants (on-rate or association rate $k_{\text {on }}$ and off-rate or dissociation rate $k_{\text {off }}$ ) and equilibrium dissociation constants $\left(K_{\mathrm{D}}\right)$ for probe-target interactions were deduced by globally fitting a set of binding curves, each of which corresponded to a concentration of the probe, to the Langmuir 1-to-1 reaction model. ${ }^{(47-49)}$

\section{Results and Discussion}

\subsection{VEGF/KDR experiment}

The microarray composed of VEGF, KDR, and their corresponding antibodies was reacted with 4 protein probes (anti-VEGF antibody v-6-2, anti-KDR antibody v2, VEGF, and KDR) at respective concentrations. Figure 2 shows the association-dissociation

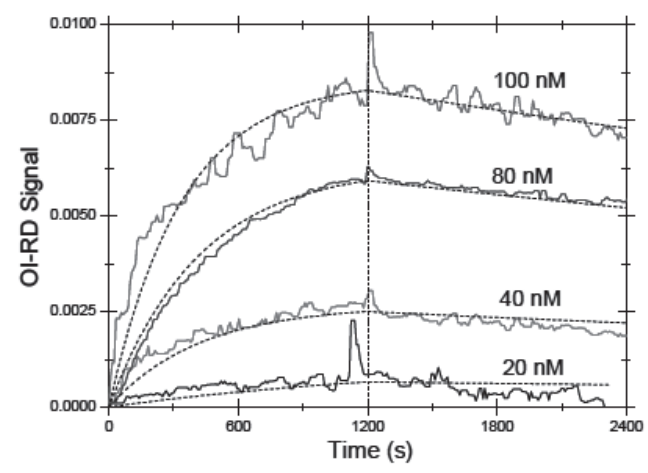

(a)

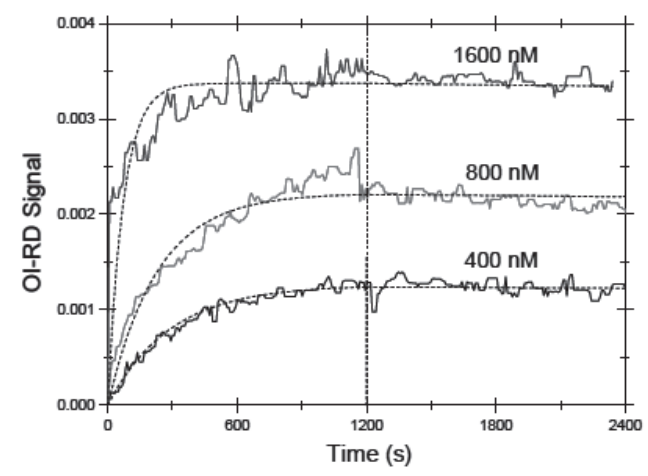

(c)

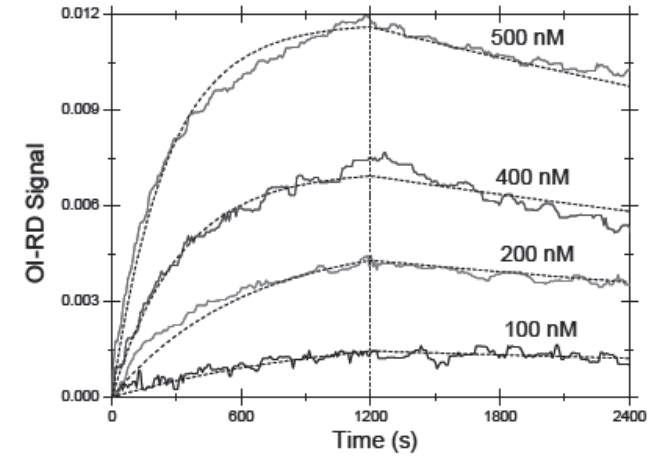

(b)

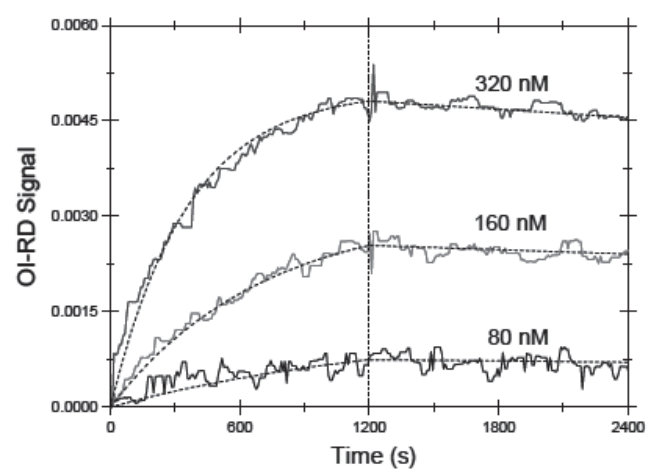

(d)

Fig. 2. Association-dissociation curves of (a) anti-VEGF antibody v-6-2 reacting with surfaceimmobilized VEGF, (b) KDR reacting with surface-immobilized anti-KDR antibody v2, (c) VEGF reacting with surface-immobilized anti-VEGF antibody v-6-2VEGF, and (d) anti-KDR antibody v2 reacting with surface-immobilized KDR. The curves in each panel were fitted globally to the onesite model (fits are shown by dashed lines) with all fitting parameters listed in Table 2. 
curves of (a) anti-VEGF antibody v-6-2 to surface-immobilized VEGF, (b) KDR to surface-immobilized anti-KDR antibody v2, (c) VEGF to surface-immobilized antiVEGF antibody v-6-2VEGF, and (d) anti-KDR antibody v2 to surface-immobilized KDR. Different probe concentrations are indicated next to the curves. The probe solution was introduced to the microarray in $1 \times$ PBS at $t=0$, and then the solution was replaced with fresh $1 \times$ PBS at $t=1200 \mathrm{~s}$ (marked by the dashed line) for another $1200 \mathrm{~s}$. Each set of binding curves was globally fitted, as shown by dotted lines in Fig. 2, and all fitting parameters are listed in Table 2. There are some noteworthy results in Fig. 2 and Table 2. First, comparison of Figs. 2(a) with 2(c) for VEGF reactions with its antibody shows that anti-VEGF reacting with surface-immobilized VEGF [panel (a), probe concentrations ranged from 20 to $100 \mathrm{nM}$ ] gave much higher signals than VEGF reacting with surface-immobilized anti-VEGF [panel (c), probe concentrations ranged from 400 to $1600 \mathrm{nM}$ ]. In contrast, comparison of Figs. 2(b) with 2(d) for KDR reactions with its antibody shows that KDR reacting with surface-immobilized anti-KDR [panel (b), probe concentration of $400 \mathrm{nM}$ had an OI-RD signal of 0.007] had higher signals than anti-KDR reacting with surface-immobilized KDR [panel (d), probe concentration of $320 \mathrm{nM}$ had an OI-RD signal of 0.005]. These results are related to the orientations and distributions of the surface-immobilized targets, the availabilities and accessibilities of the binding epitopes, and the properties of the solution-phase probes. Second, the binding affinities for VEGF and KDR reactions with their corresponding antibodies $\left(K_{\mathrm{D}}\right.$ of $\mathrm{nM}$ to tens of $\mathrm{nM})$ are comparable to those for typical antibody-antigen reactions. ${ }^{(50,51)}$ These small $K_{\mathrm{D}}$ values imply that anti-VEGF antibody v-6-2 and anti-KDR antibody v2 have potential as efficient drug candidates in anti-VEGF therapies. Thirdly, in addition to the signals, the binding affinities are different depending on whether the probes are antigens or antibodies. VEGF reacting with surface-immobilized anti-VEGF ( $K_{\mathrm{D}}$ of 0.97 $\mathrm{nM})$ had higher affinity than the reverse $\left(K_{\mathrm{D}}\right.$ of $\left.3.71 \mathrm{nM}\right)$, while anti-KDR reacting with surface-immobilized KDR $\left(K_{\mathrm{D}}\right.$ of $\left.5.32 \mathrm{nM}\right)$ had higher affinity than the reverse $\left(K_{\mathrm{D}}\right.$ of $19.3 \mathrm{nM})$. Again, these are related to the configurations of the targets, the probes, and the involved binding epitopes. The results also suggest that, when studying an antibodyantigen reaction, it is relevant to either react the free antigen with surface-immobilized antibody or the reverse.

\subsection{Oligosaccharide-lectin experiment}

Figure 3 shows the association-dissociation curves of (a) ConA, (b) WGA, and (c) LTA reacting with 16 surface-immobilized oligosaccharides. The concentration of each

Table 2

Fitting parameters of VEGF, anti-VEGF, KDR, and anti-KDR reacting with surface-immobilized binding partners.

\begin{tabular}{lcccc}
\hline Target & Probe & $k_{\text {on }}(\mathrm{nM} \mathrm{s})^{-1}$ & $k_{\text {off }}(\mathrm{s})^{-1}$ & $K_{\mathrm{D}}(\mathrm{nM})$ \\
\hline Anti-VEGF v-6-2 & VEGF & $2.86 \times 10^{-5}$ & $1.06 \times 10^{-4}$ & 3.71 \\
VEGF & Anti-VEGF v-6-2 & $8.67 \times 10^{-6}$ & $8.38 \times 10^{-6}$ & 0.97 \\
Anti-KDR v2 & KDR & $8.62 \times 10^{-6}$ & $4.59 \times 10^{-5}$ & 5.32 \\
KDR & Anti-KDR v2 & $7.5 \times 10^{-6}$ & $1.45 \times 10^{-4}$ & 19.3 \\
\hline
\end{tabular}




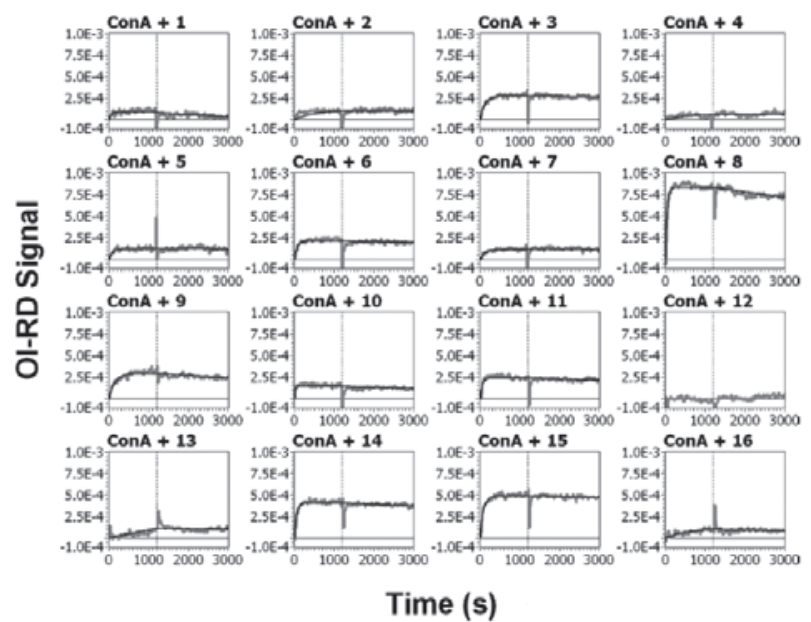

(a)

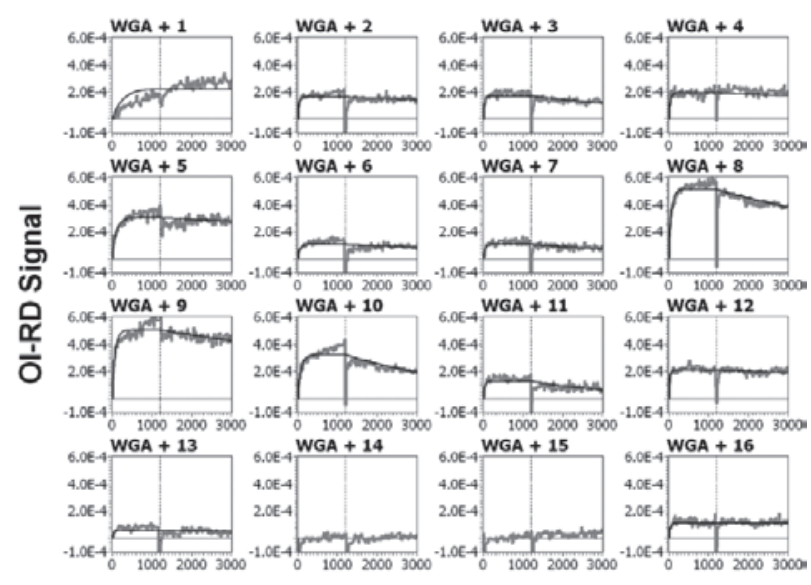

Time (s)

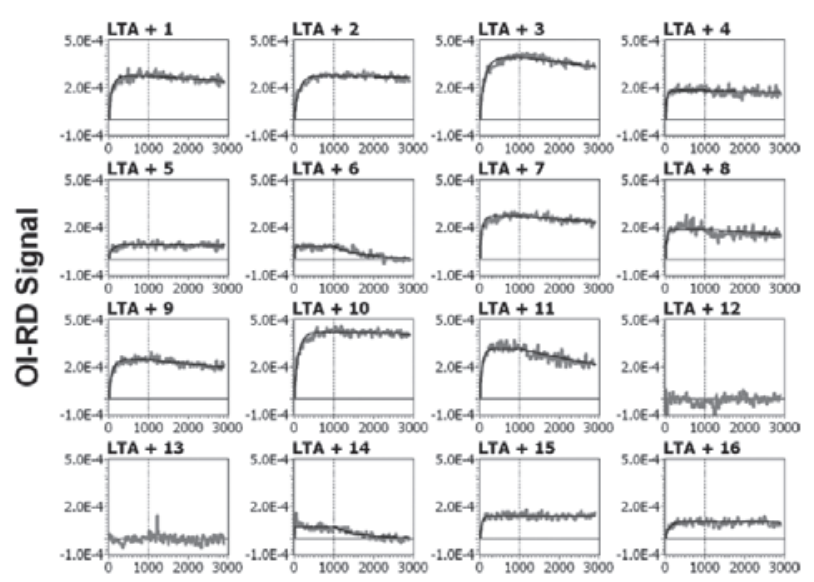

Time (s)

(b)

(c)

Fig. 3. Association-dissociation curves of (a) ConA, (b) WGA, and (c) LTA reacting with surfaceimmobilized oligosaccharides. The concentration of each lectin probe was $0.2 \mathrm{mg} / \mathrm{ml}$. Each curve was fitted to the one-site model (fits are shown by black lines) with all fitting parameters listed in Tables 3-5.

lectin probe was $0.2 \mathrm{mg} / \mathrm{ml}$. The probe solution was brought to the microarray in buffer (Tris or $1 \times$ PBS) at $t=0$, and then it was replaced with fresh buffer at $t=1200 \mathrm{~s}$ for another 2400 s. For each oligosaccharide, one representative curve out of 2 copies was selected for display. Each curve representing a specific lectin-oligosaccharide was fitted as shown by black lines in Fig. 3. The fitting parameters are listed in Table 3 for ConA, Table 4 for WGA, and Table 5 for LTA. As listed in the second and third columns of Table 3, lectin 
Table 3

Reaction results and fitting parameters (one-site model) of ConA reacting with surface-immobilized oligosaccharides.

\begin{tabular}{lccccc}
\hline $\begin{array}{l}\text { Sample } \\
\text { name }\end{array}$ & $\begin{array}{c}\text { Number of } \\
\text { hexose }\end{array}$ & $\begin{array}{c}\text { React with } \\
\text { ConA? }\end{array}$ & $k_{\text {on }}(\mathrm{nM} \mathrm{s})^{-1}$ & $k_{\text {off }}(\mathrm{s})^{-1}$ & $K_{\mathrm{D}}(\mathrm{nM})$ \\
\hline 1 & 3 & YES & $1.22 \times 10^{-5}$ & $4.61 \times 10^{-4}$ & 37.79 \\
2 & 3 & YES & $6.69 \times 10^{-6}$ & $<9.0 \times 10^{-6}$ & $<2.19$ \\
3 & 4 & YES & $4.69 \times 10^{-6}$ & $1.92 \times 10^{-5}$ & 4.09 \\
4 & 4 & YES & $6.39 \times 10^{-6}$ & $<5.72 \times 10^{-5}$ & $<8.95$ \\
5 & 4 & YES & $6.85 \times 10^{-6}$ & $<1.5 \times 10^{-5}$ & $<2.19$ \\
6 & 4 & YES & $8.61 \times 10^{-6}$ & $3.62 \times 10^{-5}$ & 4.2 \\
7 & 5 & YES & $4.1 \times 10^{-6}$ & $<3.9 \times 10^{-5}$ & $<9.51$ \\
8 & 5 & YES & $1.32 \times 10^{-5}$ & $8.01 \times 10^{-5}$ & 6.07 \\
9 & 5 & YES & $3.58 \times 10^{-6}$ & $1.08 \times 10^{-4}$ & 30.16 \\
10 & 6 & YES & $3.02 \times 10^{-5}$ & $9.76 \times 10^{-5}$ & 3.23 \\
11 & 6 & YES & $1.04 \times 10^{-5}$ & $5.7 \times 10^{-5}$ & 5.48 \\
12 (NNN) & & NO & & & \\
13 & 2 & YES & $1.92 \times 10^{-5}$ & $3.85 \times 10^{-5}$ & 2.01 \\
14 (Hex) & 6 & YES & $1.10 \times 10^{-5}$ & $4.91 \times 10^{-5}$ & 5.86 \\
15 (Hept) & 7 & YES & $6.62 \times 10^{-6}$ & $2.21 \times 10^{-5}$ & 3.34 \\
16 (Mix) & & YES & $9.27 \times 10^{-7}$ & $8.33 \times 10^{-5}$ & 89.86 \\
\hline
\end{tabular}

Table 4

Reaction results and fitting parameters (one-site model) of WGA reacting with surface-immobilized oligosaccharides.

\begin{tabular}{|c|c|c|c|c|c|}
\hline $\begin{array}{l}\text { Sample } \\
\text { name }\end{array}$ & $\begin{array}{c}\text { Number of } \\
\text { HexNAc }\end{array}$ & $\begin{array}{c}\text { React with } \\
\text { WGA? }\end{array}$ & $k_{\text {on }}(\mathrm{nM} \mathrm{s})^{-1}$ & $k_{\text {off }}(\mathrm{s})^{-1}$ & $K_{\mathrm{D}}(\mathrm{nM})$ \\
\hline 1 & 1 & YES & $2.09 \times 10^{-6}$ & $<2.73 \times 10^{-5}$ & $<13.06$ \\
\hline 2 & 1 & YES & $1.81 \times 10^{-5}$ & $6.3 \times 10^{-5}$ & 3.84 \\
\hline 3 & 2 & YES & $1.8 \times 10^{-5}$ & $2.02 \times 10^{-4}$ & 11.22 \\
\hline 4 & 2 & YES & $2.05 \times 10^{-5}$ & $<3 \times 10^{-6}$ & $<0.15$ \\
\hline 5 & 2 & YES & $5.35 \times 10^{-6}$ & $4.86 \times 10^{-5}$ & 9.08 \\
\hline 6 & 2 & YES & $1.17 \times 10^{-5}$ & $1.25 \times 10^{-4}$ & 10.68 \\
\hline 7 & 3 & YES & $1.26 \times 10^{-5}$ & $2.1 \times 10^{-4}$ & 16.67 \\
\hline 8 & 3 & YES & $9 \times 10^{-6}$ & $1.58 \times 10^{-4}$ & 17.56 \\
\hline 9 & 3 & YES & $7.48 \times 10^{-6}$ & $9.84 \times 10^{-5}$ & 13.16 \\
\hline 10 & 4 & YES & $6.91 \times 10^{-6}$ & $2.7 \times 10^{-4}$ & 39.07 \\
\hline 11 & 4 & YES & $1.6 \times 10^{-5}$ & $3.91 \times 10^{-4}$ & 24.43 \\
\hline $12(\mathrm{NNN})$ & 3 & YES & $2.22 \times 10^{-5}$ & $5.73 \times 10^{-5}$ & 2.58 \\
\hline 13 & & YES & $1.61 \times 10^{-5}$ & $8.29 \times 10^{-5}$ & 5.15 \\
\hline 14 (Hex) & & $\mathrm{NO}$ & & & \\
\hline 15 (Hept) & & $\mathrm{NO}$ & & & \\
\hline 16 (Mix) & & YES & $1.75 \times 10^{-5}$ & $<3.8 \times 10^{-5}$ & $<2.17$ \\
\hline
\end{tabular}


Table 5

Reaction results and fitting parameters (one-site model) of LTA reacting with surface-immobilized oligosaccharides.

\begin{tabular}{|c|c|c|c|c|c|}
\hline $\begin{array}{l}\text { Sample } \\
\text { name }\end{array}$ & $\begin{array}{l}\text { Number of } \\
\text { fucose }\end{array}$ & $\begin{array}{l}\text { React with } \\
\text { LTA? }\end{array}$ & $k_{\mathrm{on}}(\mathrm{nM} \mathrm{s})^{-1}$ & $k_{\text {off }}(\mathrm{s})^{-1}$ & $K_{\mathrm{D}}(\mathrm{nM})$ \\
\hline 1 & & YES & $7.14 \times 10^{-6}$ & $5.85 \times 10^{-5}$ & 8.19 \\
\hline 2 & 1 & YES & $5 \times 10^{-6}$ & $<1.3 \times 10^{-5}$ & $<2.6$ \\
\hline 3 & & YES & $4.65 \times 10^{-6}$ & $6.76 \times 10^{-5}$ & 14.53 \\
\hline 4 & 1 & YES & $1.72 \times 10^{-5}$ & $5.34 \times 10^{-6}$ & 0.31 \\
\hline 5 & 2 & YES & $9.18 \times 10^{-6}$ & $1.79 \times 10^{-5}$ & 1.95 \\
\hline 6 & 3 & YES & $2.78 \times 10^{-5}$ & $1.74 \times 10^{-3}$ & 62.59 \\
\hline 7 & 1 & YES & $1.1 \times 10^{-5}$ & $7.34 \times 10^{-3}$ & 6.67 \\
\hline 8 & 2 & YES & $1.85 \times 10^{-5}$ & $4.56 \times 10^{-5}$ & 2.46 \\
\hline 9 & 3 & YES & $6.72 \times 10^{-6}$ & $1.1 \times 10^{-4}$ & 16.37 \\
\hline 10 & 2 & YES & $5.54 \times 10^{-6}$ & $<8 \times 10^{-6}$ & $<1.44$ \\
\hline 11 & 3 & YES & $1.04 \times 10^{-5}$ & $1.55 \times 10^{-4}$ & 14.9 \\
\hline $12(\mathrm{NNN})$ & & NO & & & \\
\hline 13 & & $\mathrm{NO}$ & & & \\
\hline 14 (Hex) & & YES & $1.88 \times 10^{-4}$ & $1.98 \times 10^{-3}$ & 10.53 \\
\hline 15 (Hept) & & YES & $1.02 \times 10^{-5}$ & $1.16 \times 10^{-5}$ & 1.13 \\
\hline 16 (Mix) & & YES & $5.61 \times 10^{-6}$ & $<2.17 \times 10^{-5}$ & $<3.87$ \\
\hline
\end{tabular}

ConA binds to all hexose-containing oligosaccharides (Samples 1-11 and 13-16), as expected. With $k_{\text {on }}$ in the order of $10^{-6}-10^{-5}(\mathrm{nM} \mathrm{s})^{-1}$ and $k_{\text {off }}$ in the order of $10^{-5}(\mathrm{~s})^{-1}$, the equilibrium dissociation constant $K_{\mathrm{D}}$ for the present ConA-oligosaccharide interactions is roughly of nM order except for Samples 1 (37.8 nM), 9 (30.2 nM), and 16 (89.9 nM). Table 4 indicates that lectin WGA interacts with all HexNAc-containing oligosaccharides (Samples 1-12 and 16) as anticipated. However, unusually, it also binds to Sample 13, which does not contain HexNAc. For the present WGA-oligosaccharide interactions, with $k_{\text {on }}$ in the order of $10^{-6}-10^{-5}(\mathrm{nM} \mathrm{s})^{-1}$ and $k_{\text {off }}$ in the order of $10^{-5}-10^{-4}(\mathrm{~s})^{-1}, K_{\mathrm{D}}$ ranges from 3 to $39 \mathrm{nM}$ except for Samples $4(<0.15 \mathrm{nM})$ and $16(<2.17 \mathrm{nM})$. As shown in Table 5, lectin LTA binds to all fucose-containing oligosaccharides (Samples 2 and 4-11) as expected, but also to Samples 1, 3, and 14-16, all without fucose. $K_{\mathrm{D}}$ for the present LTA-oligosaccharide interactions ranges from 2 to $15 \mathrm{nM}$, except for Samples $2(<2.6 \mathrm{nM}), 4(0.31 \mathrm{nM}), 10(<1.44 \mathrm{nM}), 15(1.13 \mathrm{nM})$, and $16(<3.87 \mathrm{nM})$ with very small $K_{\mathrm{D}}$, and Sample $6(62.6 \mathrm{nM})$ with very large $K_{\mathrm{D}}$. Overall, from Fig. 3 and Tables $3-5$, the binding specificity between lectins and oligosaccharides in the present study corresponds as expected. Some uncommon interactions in WGA and LTA might be due to nonspecific bindings or simply incompletely separate oligosaccharides in sample preparation.

\subsection{Small molecular microarray experiment}

A small molecular microarray was reacted with a 1:10 diluted Jurkat cell lysate solution. Figure 4(a) shows the association-dissociation curves of the cell lysate reacting 

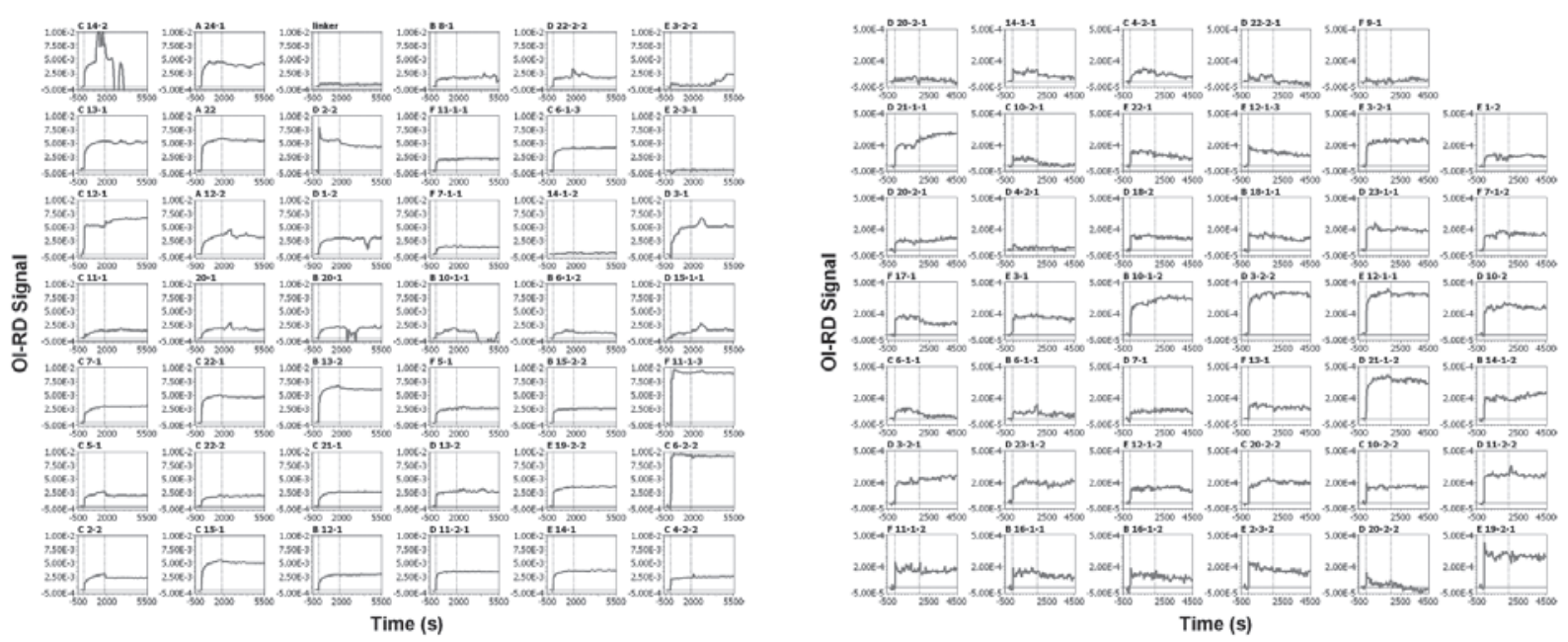

\begin{tabular}{|c|c|c|c|c|c|}
\hline . & A 24-1 Y & linker & Ba.4 द्व & ${ }^{0}$ 22-2-2 380 & $\mathrm{E}^{\mathrm{B} \cdot 2 \cdot 2 \cdot 2}$ \\
\hline 805 & $\begin{array}{l}\text { A22 } \\
\text { Sos }\end{array}$ & $\begin{array}{c}02-2 \\
0 \\
80\end{array}$ & 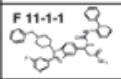 & 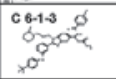 & $\frac{a^{2}}{g^{2-1}-1}$ \\
\hline $\begin{array}{l}c_{12-1} \\
629 \\
0-0\end{array}$ & $\begin{array}{l}\text { A 12:2 } \\
280 \\
28\end{array}$ & 8 & 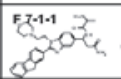 & & din \\
\hline & & & & B $6-1$ & \\
\hline & 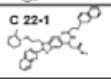 & $\begin{array}{l}\text { B, } 13 \cdot 2 \\
62 \\
60\end{array}$ & & & $\begin{array}{l}\text { F11-1-s } \\
\text { ong. }\end{array}$ \\
\hline $\begin{array}{l}\text { cs-1 } \\
805 \\
5\end{array}$ & & c21-1 & $\begin{array}{l}013-2 \text { b } \\
0,050\end{array}$ & 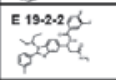 & 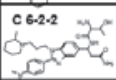 \\
\hline${ }^{12.2}=0$ & c 15-1 & & $0^{1112-1} z^{-1}$ & 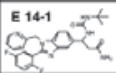 & $c 4 \cdot 2 \cdot 2$ \\
\hline
\end{tabular}

\begin{tabular}{|c|c|c|c|c|c|}
\hline $\begin{array}{l}020-2 \cdot 2 \\
0 \\
0\end{array}$ & $\begin{array}{l}14-1 \cdot 3 \\
\text { recto }\end{array}$ & 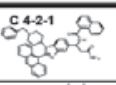 & 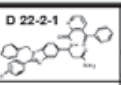 & $x^{9-1} \sigma_{2}$ & \\
\hline${ }^{021-1-1}$ & dn & $\begin{array}{l}\text { E22-1 } 8 \\
000\end{array}$ & $8^{12-13}$ & $\mathrm{C}^{3-2-1}$ & 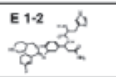 \\
\hline D20-2-1 & $\begin{array}{l}042 \cdot 1 \\
\text { dings }\end{array}$ & D 18-2 & & & \\
\hline$f^{17-1}$ & E3-1 & B 10.1-2. & $\overbrace{8}^{03-2 \cdot 2} x^{2}$ & & \\
\hline & 8 6 6-1. & $\begin{array}{l}07.1 z^{6} \\
\text { of }^{2} 0^{2}\end{array}$ & $\begin{array}{l}\text { F 13.1 } \\
\text { cot }\end{array}$ & $b^{21 \cdot 1 \cdot 2}=\alpha$ & \\
\hline & $8^{23-1-2}$ & E12-1.2. & c 20.2 & 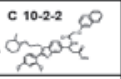 & $\begin{array}{l}011-2 \cdot 2 \text { od } \\
0 a^{2} c^{2} \\
00\end{array}$ \\
\hline Fas & $\begin{array}{l}816-1 \cdot 1 \\
80.6 \\
8\end{array}$ & 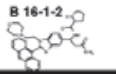 & & & 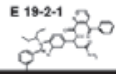 \\
\hline
\end{tabular}

(a)

(b)

Fig. 4. (a) Real-time binding curves of a 1:10 diluted Jurkat cell lysate solution reacting with the first SMM of 42 small molecules (top panel). The chemical structures of these 42 small molecules are shown in the bottom panel in the same order. (b) Real-time binding curves of a 1:10 diluted Jurkat cell lysate solution reacting with the second SMM of 41 small molecules (top panel). The chemical structures of these 41 small molecules are shown in the bottom panel in the same order.

with the first 42 small molecules. The corresponding chemical structures of these small molecules are shown in the bottom panel. The cell lysate solution was brought to the microarray in $1 \times \mathrm{PBS}$ at $t=0$, and then the solution was replaced with fresh $1 \times \mathrm{PBS}$ at $t=1800 \mathrm{~s}$ for another $3600 \mathrm{~s}$. The OI-RD signals for all small molecules, except for E 3-2-2, E 2-3-1, and 14-1-1, are $2 \times 10^{-3}-1 \times 10^{-2}$. In addition, all small molecules that reacted with the Jurkat cell lysate have equilibrium dissociation constants in the 
$\mathrm{nM}$ range. Further identification of the captured proteins and more curves determined with different lysate dilutions are necessary to enable global fittings for accurate reaction constants. Figure 4(b) shows the association-dissociation curves of the cell lysate reacting with the second set of 41 small molecules. The corresponding chemical structures of these small molecules are shown in the bottom panel. Except for D 20-2-1, D 4-2-1, D 22-2-1, D 20-2-2, and F 9-1, the OI-RD signals for all small molecules in this batch are $1 \times 10^{-4}-4 \times 10^{-4}$, which are much smaller than those in the first batch. Again, all reacted small molecules bound to the Jurkat cell lysate with equilibrium dissociation constants in the $\mathrm{nM}$ range. The identity of captured proteins and the affinity to these proteins are related to the nature of these small molecules. The first batch of microarrays was also reacted with cDNA phages used to display and select the present small molecules. Figure 5 shows the real-time binding curves of a 1:20 diluted cDNA phage solution reacting with the first set of 42 small molecules. In general, the OI-RD
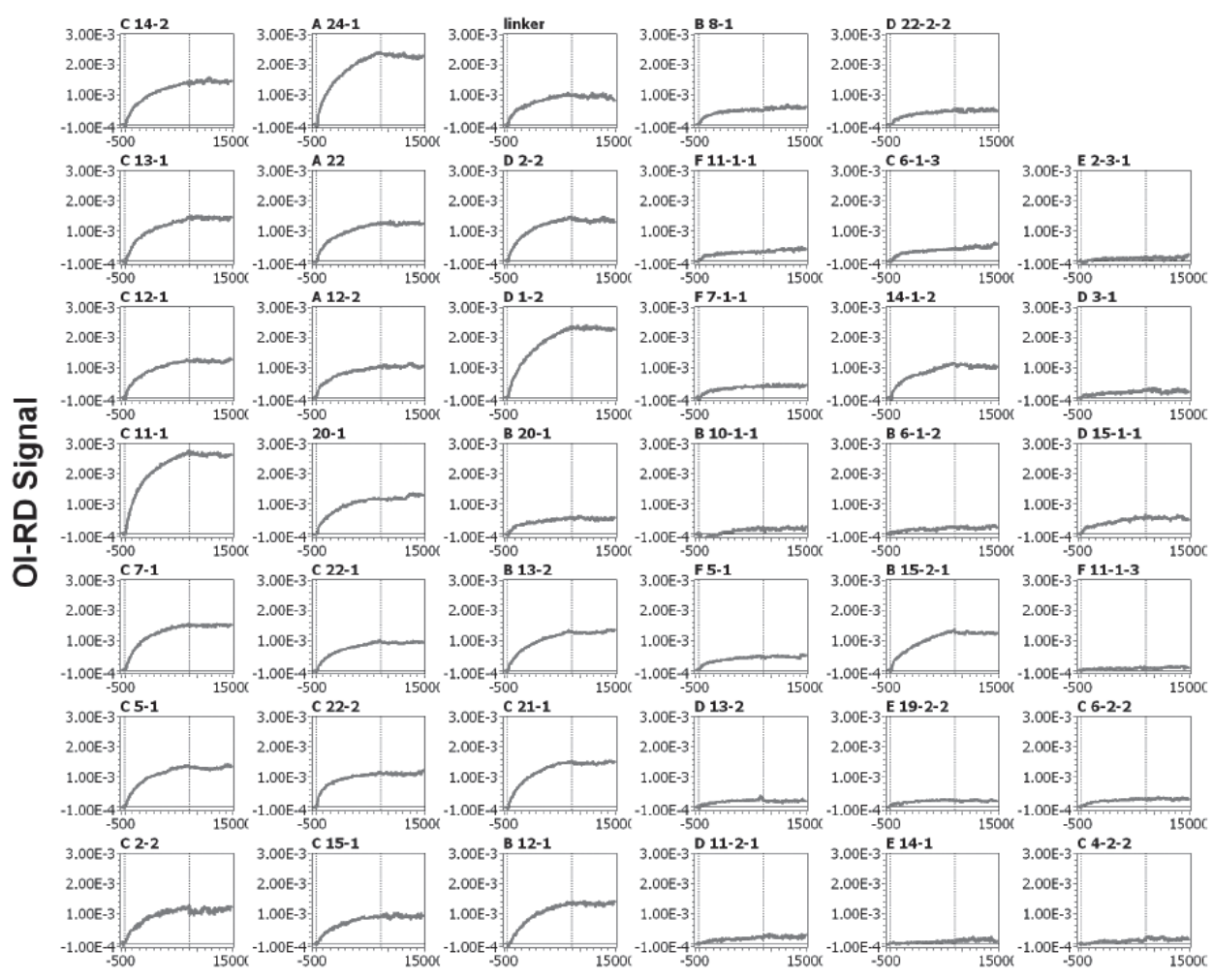

Time (s)

Fig. 5. Real-time binding curves of a 1:20 diluted cDNA phage solution reacting with the first SMM of 42 small molecules (top panel). The chemical structures of these 42 small molecules are shown in the same order, as in Fig. 4(a). 
signals for all small molecules are less than $3 \times 10^{-3}$, and the binding affinities are much lower (equilibrium NOT reached in $3 \mathrm{~h}$ ) than $\mathrm{nM}$ values in the case of cell lysate (equilibrium was reached within 3 to $4 \mathrm{~min}$ ). This is because these phages are bulkier than proteins and hence they need more time to orient themselves into a dynamically stable state.

\section{Conclusions}

Using a combination of the microarray platform and label-free OI-RD microscopes, we studied the binding kinetics of various novel biomolecular interactions. The conclusions are as follows.

(1) VEGF/KDR experiment: The binding kinetics of VEGF and KDR interacting with their corresponding antibodies were studied. The results showed that the binding affinities of these reactions are comparable to those measured in typical antibody-antigen reactions, and are also dependent on whether the probes are antigens or antibodies. The strong binding of these antibodies to VEGF and KDR (indicated by small $K_{\mathrm{D}}$ values ranging from $\mathrm{pM}$ to $\mathrm{nM}$ order) suggests that they are promising as efficient drug candidates to block the VEGF/KDR pathway. In the future, using microarrays for highthroughput screening, and OI-RD microscopes for real-time detection, one can test the efficiency, stability, and durability of potential antibodies and inhibitors in anti-VEGF therapies.

(2) Oligosaccharide-lectin experiment: Sets of specificity and affinity measurements of lectin-oligosaccharide interactions were performed. In the future, with more and more HMOs being identified and separated, one will be able to profile and characterize all oligosaccharides in human milk with a combination of immobilization and detection techniques mentioned here.

(3) Small molecular microarray experiment: We demonstrated the use of the OI$\mathrm{RD}$ microscope to measure the kinetics of small molecule-cell lysate and small moleculecDNA phage interactions. The results indicated that a combination of the SMM platform and an OI-RD microscope for detection is applicable to fast and high-throughput screening of potential protein ligands. Moreover, to further determine the identities of all captured proteins, it is necessary to develop a sample-holding cartridge that enables the transfer of slides with reacted microarrays to a mass spectrometer for mass identification.

\section{Acknowledgements}

The authors are grateful for the financial support from NIH-R01-HG003827 (X. D. Zhu) and Taiwan NSC 101-2112-M-030-003-MY3 (Y. S. Sun).

\section{References}

1 J. P. Landry, Y. S. Sun, X. W. Guo and X. D. Zhu: Appl. Opt. 47 (2008) 3275.

2 Y. S. Sun, J. P. Landry, Y. Y. Fei, X. D. Zhu, J. T. Luo, X. B. Wang and K. S. Lam: Langmuir 24 (2008) 13399. 
3 Y. Fei, Y. S. Sun, Y. Li, K. Lau, H. Yu, H. A. Chokhawala, S. Huang, J. P. Landry, X. Chen and X. Zhu: Mol. Biosyst. 7 (2011) 3343.

4 Y. Fei, J. P. Landry, Y. Sun, X. Zhu, X. Wang, J. Luo, C. Y. Wu and K. S. Lam: J. Biomed. Opt. 15 (2010) 016018.

5 J. P. Landry, Y. Fei and X. D. Zhu: Int. Drug Discovery 6 (2011) 8.

6 J. P. Landry, Y. Fei and X. Zhu: Assay Drug. Dev. Technol. 10 (2012) 250.

7 Y. S. Sun, J. P. Landry, Y. Y. Fei, X. D. Zhu, J. T. Luo, X. B. Wang and K. S. Lam: Anal. Chem. 81 (2009) 5373.

8 N. Ferrara: Endocrine Rev. 25 (2004) 581.

9 D. J. Hicklin and L. M. Ellis: J. Clin. Oncol. 23 (2005) 1011.

10 R. K. Jain: Nat. Med. 7 (2001) 987.

11 R. K. Jain: Science 307 (2005) 58.

12 H. P. Gerber and N. Ferrara: Cancer Res. 65 (2005) 671.

13 J. Waltenberger, L. Claesson-Welsh, A. Siegbahn, M. Shibuya and C. H. Heldin: J. Biol. Chem. 269 (1994) 26988.

14 B. I. Terman, M. Dougher-Vermazen, M. E. Carrion, D. Dimitrov, D. C. Armellino, D. Gospodarowicz and P. Bohlen: Biochem. Biophys. Res. Commun. 187 (1992) 1579.

15 B. Millauer, S. Wizigmann-Voos, H. Schnurch, R. Martinez, N. P. Moller, W. Risau and A. Ullrich: Cell 72 (1993) 835.

16 T. P. Quinn, K. G. Peters, C. De Vries, N. Ferrara and L. T. Williams: Proc. Natl. Acad. Sci. U.S.A. 90 (1993) 7533.

17 C. de Vries, J. A. Escobedo, H. Ueno, K. Houck, N. Ferrara and L. T. Williams: Science 255 (1992) 989.

18 M. Relf, S. LeJeune, P. A. Scott, S. Fox, K. Smith, R. Leek, A. Moghaddam, R. Whitehouse, R. Bicknell and A. L. Harris: Cancer Res. 57 (1997) 963.

19 M. Stimpfl, D. Tong, B. Fasching, E. Schuster, A. Obermair, S. Leodolter and R. Zeillinger: Clin. Cancer Res. 8 (2002) 2253.

20 S. Baka, A. R. Clamp and G. C. Jayson: Expert Opin. Ther. Targets 10 (2006) 867.

21 L. G. Presta, H. Chen, S. J. O’Connor, V. Chisholm, Y. G. Meng, L. Krummen, M. Winkler and N. Ferrara: Cancer Res. 57 (1997) 4593.

22 A. Morabito, E. De Maio, M. Di Maio, N. Normanno and F. Perrone: Oncologist 11 (2006) 753.

23 C. Kunz, S. Rudloff, W. Baier, N. Klein and S. Strobel: Annu. Rev. Nutr. 20 (2000) 699.

24 L. Bode: J. Nutr. 136 (2006) 2127.

25 M. K. Davis: Pediatr. Clin. North Am. 48 (2001) 125 ix.

26 G. Boehm and G. Moro: J. Nutr. 138 (2008) 1818S.

27 G. Schumacher, G. Bendas, B. Stahl and C. Beermann: Nutrition 22 (2006) 620.

28 M. A. Naarding, I. S. Ludwig, F. Groot, B. Berkhout, T. B. Geijtenbeek, G. Pollakis and W. A. Paxton: J. Clin. Invest. 115 (2005) 3256.

29 P. Hong, M. R. Ninonuevo, B. Lee, C. Lebrilla and L. Bode: Br. J. Nutr. 101 (2009) 482.

30 W. Chai, V. E. Piskarev, Y. Zhang, A. M. Lawson and H. Kogelberg: Arch. Biochem. Biophys. 434 (2005) 116.

31 B. Finke, B. Stahl, A. Pfenninger, M. Karas, H. Daniel and G. Sawatzki: Anal. Chem. 71 (1999) 3755.

32 J. Charlwood, D. Tolson, M. Dwek and P. Camilleri: Anal. Biochem. 273 (1999) 261.

33 M. R. Ninonuevo, R. E. Ward, R. G. LoCascio, J. B. German, S. L. Freeman, M. Barboza, D. A. Mills and C. B. Lebrilla: Anal. Biochem. 361 (2007) 15.

34 S. Thurl, B. Muller-Werner and G. Sawatzki: Anal. Biochem. 235 (1996) 202. 
35 P. Chaturvedi, C. D. Warren, G. M. Ruiz-Palacios, L. K. Pickering and D. S. Newburg: Anal. Biochem. 251 (1997) 89.

36 M. R. Ninonuevo, Y. Park, H. Yin, J. Zhang, R. E. Ward, B. H. Clowers, J. B. German, S. L. Freeman, K. Killeen, R. Grimm and C. B. Lebrilla: J. Agric. Food Chem. 54 (2006) 7471.

37 M. R. Ninonuevo, P. D. Perkins, J. Francis, L. M. Lamotte, R. G. LoCascio, S. L. Freeman, D. A. Mills, J. B. German, R. Grimm and C. B. Lebrilla: J. Agric. Food Chem. 56 (2008) 618.

38 N. Winssinger, S. Ficarro, P. G. Schultz and J. L. Harris: Proc. Natl. Acad. Sci. U.S.A. 99 (2002) 11139.

39 Q. Xu, S. Miyamoto and K. S. Lam: Mol. Diversity 8 (2004) 301.

40 N. Sharon and H. Lis: Lectins, 2nd Ed. (Springer, New York City, 2003).

41 C. L. Nilsson: Lectins, Analytical Technologies, 1st Ed. (Elsevier, Oxford, 2007).

42 O. H. Aina, J. Marik, R. Liu, D. H. Lau and K. S. Lam: Mol. Cancer Ther. 4 (2005) 806.

43 K. S. Lam: Anti-Cancer Drug Des. 12 (1997) 145.

44 K. S. Lam, R. Liu, S. Miyamoto, A. L. Lehman and J. M. Tuscano: Acc. Chem. Res. 36 (2003) 370.

45 K. S. Lam, S. E. Salmon, E. M. Hersh, V. J. Hruby, W. M. Kazmierski and R. J. Knapp: Nature 354 (1991) 82.

46 L. Peng, R. Liu, J. Marik, X. Wang, Y. Takada and K. S. Lam: Nat. Chem. Biol. 2 (2006) 381.

47 J. Majka and C. Speck: Adv. Biochem. Eng. Biotechnol. 104 (2007) 13.

48 J. Nahalkova, J. Svitel, P. Gemeiner, B. Danielsson, B. Pribulova and L. Petrus: J. Biochem. Biophys. Methods 52 (2002) 11.

49 N. Nagata and H. Handa: Real-Time Analysis of Biomolecular Interactions, Applications of BIACORE (Springer-Verlag, Tokyo, 2000).

50 P. S. Katsamba, I. Navratilova, M. Calderon-Cacia, L. Fan, K. Thornton, M. Zhu, T. V. Bos, C. Forte, D. Friend, I. Laird-Offringa, G. Tavares, J. Whatley, E. Shi, A. Widom, K. C. Lindquist, S. Klakamp, A. Drake, D. Bohmann, M. Roell, L. Rose, J. Dorocke, B. Roth, B. Luginbuhl and D. G. Myszka: Anal. Biochem. 352 (2006) 208.

51 G. A. Papalia, M. Baer, K. Luehrsen, H. Nordin, P. Flynn and D. G. Myszka: Anal. Biochem. 359 (2006) 112. 